\title{
O TEXTO COMO OBRA DE ARTE: GADAMER E O CASO DA LITERATURA
}

\author{
The text as work of art: Gadamer and the case of literature
}

Gustavo Silvano Batista

UFPI

\begin{abstract}
Resumo: Neste artigo pretendemos discutir a reflexão hermenêutica acerca da literatura, tomando como ponto central a abordagem realizada em Verdade e Método, na qual Gadamer tece considerações sobre a relação entre o texto literário e o evento da compreensão, questão diretriz de seu pensamento. Contudo, não temos como objetivo aplicar o seu pensamento nas atividades literárias, nem simplesmente sugerir métodos de interpretação de textos, mas analisar o fenômeno hermenêutico da literatura, enfatizando os elementos básicos apontados por Gadamer neste mesmo fenômeno.
\end{abstract}

Palavras-chave: Gadamer; Hermenêutica; Compreensão; Literatura; Representação

Abstract: In this paper, we have intended to discuss the hermeneutical reflection on the literature, taking as a central point the approach of Truth and Method, where Gadamer reflects on the relationship between the literary text and the understanding, a key question of his thought. However, we do not aim to apply his philosophy in the contemporary literary activities, neither simply suggest methods of interpreting texts, but rather to analyze the hermeneutical phenomenon of literature, emphasizing the basic elements pointed by Gadamer in this same phenomenon.

Keywords: Gadamer; Hermeneutics; Understanding; Literature; Representation

\section{Introdução}

$\mathrm{Na}$ primeira parte de Verdade e Método, especificamente nas reflexões dedicadas à experiência hermenêutica tal como se configura nas mais diversas expressões artísticas, Gadamer dedica uma parte adicional à literatura, analisando-a do ponto de vista da questão da compreensão, questão-chave de seu pensamento.

Ao refletir sobre alguns elementos específicos da hermenêutica filosófica no acontecimento da literatura, Gadamer indica traços importantes que, na experiência da literatura, indicam uma reflexão acerca de seu próprio pensamento. Ou seja, 
também o fenômeno da literatura, enquanto obra de arte, é também marcada por uma estrutura representativa que pode ser pensada enquanto modo de ser do texto; e, ao mesmo tempo, este mesmo acontecer da literatura pode ser considerado como um momento decisivo da natureza da própria literatura.

Assim, o presente texto pretende discutir alguns elementos próprios da experiência hermenêutica da obra de arte; e, mais especificamente, o modo como a literatura constitui-se um evento, isto é, enquanto uma expressão artística pensada a partir do ponto de vista da compreensão, aparecendo então como uma manifestação artística do próprio texto.

\section{Compreensão e experiência da obra de arte}

Para Gadamer, a experiência da arte constitui-se como um modelo no qual o compreender acontece de um modo sempre renovado. Em outras palavras, compreender ontologicamente uma obra de arte significa também experimentá-la em seu modo mais básico, ou seja, em sua aparição e repercussão no mundo que a circunda.

Contudo, a consideração filosófica de tal experiência requer também uma justa reflexão que abre um âmbito de investigação do modo de processar desta própria experiência. Deste modo, em Gadamer, a reflexão hermenêutica da arte pretende inaugurar um horizonte de indagação que se situa em uma esfera mais original, isto é, no âmbito do acontecer da compreensão enquanto momento básico de nossa relação com as coisas em geral. Por essa razão, a experiência da obra de arte é um modelo no qual podemos descrever o próprio acontecimento do compreender. Neste sentido, Gadamer visa não apenas reconsiderar os elementos próprios de uma experiência da verdade própria da arte, mas também repensar a própria filosofia, revendo os pressupostos inerentes a esta atividade e ainda não devidamente questionados.

Visando sustentar um modelo de pensamento que afirma, por um lado, uma investigação livre e racional acerca das coisas tais como se mostram e, por outro lado, a elucidação de uma esfera de sentido pressuposta que nos atinge por meio da 
linguagem, Gadamer realiza uma crítica à filosofia, especialmente em sua expressão moderna, como um momento no qual se sedimentou uma experiência de pensamento racional que se compreendia de modo auto-suficiente. Nesta empreitada, Gadamer parte da apresentação da estrutura básica do compreender, tal como se dá na experiência da obra de arte. Este seria um dos momentos no qual poderíamos visualizar uma experiência de verdade não-objetiva, não mais submetida ao domínio abstrato de um método, que se sustenta a partir do esquema representativo da relação sujeito e objeto enquanto uma estrutura pressuposta e, por isso mesmo, não devidamente questionada.

Assim, ao discutir a estrutura representativa própria da modernidade, Gadamer realiza um movimento de retorno a uma estrutura anterior que, a seu ver, seria compatível com uma experiência de pensamento não dogmático, tal como ele pretende estruturar a hermenêutica filosófica. Como afirma Richard J. Bernstein,

O objetivo primeiro de Gadamer é expor o erro de um modelo de pensamento que se move entre pólos contrários e abrir-nos um novo caminho de pensamento no qual a compreensão revela que nosso ser-nomundo foi distorcido quando impusemos conceitos de objetividade e relativismo ${ }^{1}$.

Para tornar mais claro esse novo modelo representativo, Gadamer recorre à discussão acerca da representação na pintura que, consequentemente, se estende às outras manifestações artísticas, como por exemplo o teatro, a música, a arquitetura, etc. Para Gadamer, a experiência das artes oferece-nos a possibilidade de visualizarmos uma estrutura representativa crítica ao modelo moderno, permitindo assim entender o acontecimento compreensivo de forma decisiva.

Neste sentido, a experiência da verdade na arte não pode ser pensada de modo satisfatório a partir da estrutura representativa moderna. Pela sua própria natureza, esta experiência deve ser pensada a partir de um novo modelo de representação que, ao mesmo tempo, revisa os próprios pressupostos sustentados por essa mesma estrutura representativa. Isto quer dizer que o projeto gadameriano não

${ }^{1}$ BERNSTEIN, Richard J. Beyond Objectivism and Relativism: Science, hermeneutics and praxis. Oxford: Basil Blackwell, 1983.p. 115. 
se submete a uma ordem de significação fundada na relação dicotômica entre sujeito e objeto, ainda fortemente atuante numa concepção de racionalidade calculativa. Pelo contrário: ao buscar na experiência da arte um modelo para pensar a própria estrutura de seu pensamento, Gadamer vislumbra uma esfera pressuposta e decisiva que, a seu ver só poderia ser pensada a partir de uma atitude crítica ao modelo moderno de racionalidade. Assim, é na experiência da arte que temos um modelo para pensar a razão hermenêutica. Poderíamos ainda afirmar que na relação interpretativa entre sujeitos e obras de arte é possível entender o modo como o compreender acontece.

Para Gadamer, é necessário dar um passo atrás aos desenvolvimentos filosóficos modernos, isto é, retornar a um paradigma representativo que evidencie como estrutural o aspecto de interação entre o sujeito, entendido agora como intérprete, e o objeto, tomado como a coisa a ser compreendida que, evidentemente, também questiona o próprio intérprete.

Ao considerar, a partir desta crítica, o tratamento de uma estrutura ontológica ainda não devidamente pensada, mas ainda estabelecida em um registro representativo, Gadamer busca evidenciar um modelo representativo anterior, prémoderno que, de acordo com o próprio Gadamer, desperta a possibilidade de "descobrir e tornar consciente algo que foi encoberto e ignorado por aquela disputa sobre os métodos, algo que, antes de limitar e restringir a ciência moderna precede-a e em parte torna-a possível"2.

O movimento de revisão que Gadamer direciona sua crítica ao modelo representativo moderno, é fortemente marcado pelo modo como Heidegger direciona sua crítica à história da metafísica ocidental. Todavia, ao contrário de Heidegger, Gadamer realiza sua crítica ao conceito moderno de razão, buscando a superação deste modelo através da identificação de um novo fundamento mais original. Como diz Duque-Estrada,

Enquanto Heidegger pretende sair do nível da representação, com algo inseparável da compreensão do ser como presença, Gadamer, por sua vez, não quer sair, mas restabelecer a representação em sua base mais original ${ }^{3}$.

${ }^{2}$ GADAMER, Hans-Georg. Verdade e Método I. 5a. edição. Petrópolis: Vozes, 2003, p.15.

${ }^{3}$ DUQUE-ESTRADA, Paulo Cesar. Is hermeneutics a keyword to characterize Heidegger's thought? Inédito, 2008, p. 10. 
Desta forma, o retorno a uma estrutura representativa pré-moderna significa, do ponto de vista de Gadamer, estabelecer um modelo compatível com o acontecimento da compreensão, que ao mesmo tempo abra este âmbito mais original de manifestação das coisas em geral. Ainda nas palavras de Duque-Estrada:

O movimento gadameriano de retorno a um âmbito mais original do que aquele dos fundamentos postos pela metafísica não pretende - ao contrário do movimento que Heidegger realiza neste mesmo sentido e já no seu projeto inicial de uma ontologia fundamental - ir além ou aquém da mediação lingüística do sentido ${ }^{4}$.

Gadamer, no final da primeira parte de Verdade e Método, apresenta a formulação de uma estrutura alternativa de representação. Partindo da argumentação de Gadamer, a experiência da obra de arte, que deve ser distinta dos desenvolvimentos da estética (que, do ponto de vista de Gadamer, ainda se encontra vinculada ao modelo representacional moderno, no qual haveria um ideal de dominação do objeto artístico por parte de um sujeito), pode ser descrita a partir de um novo modelo representativo que faz justiça ao acontecer da verdade na arte, permitindo que a própria obra de arte tenha algo a dizer ao seu interlocutorintérprete.

Para re-situar a obra de arte na esfera básica e original da experiência (Erfahrung) comum, Gadamer recorre à palavra latina representation (Repräesentation), herança greco-cristã munida de caráter não objetivista que, a seu ver, libera a representação de qualquer vínculo com o esquema 'sujeito e objeto'. Cito Gadamer:

A história do significado desse termo é muito instrutiva. Um termo familiar aos romanos adquire uma mudança semântica completamente nova à luz da idéia cristã da encarnação e do corpus mysticum. Representatio já não significa somente cópia ou representação plástica (bildliche Darstellung), nem mesmo "representação", no sentido comercial de satisfazer o valor de compra, mas significa agora "representação" (Vertreteung), no sentido de

${ }^{4}$ DUQUE-ESTRADA, Paulo Cesar. 'Limites da Herança Heideggeriana: a Práxis na Hermenêutica de Gadamer'. In Revista Portuguesa de Filosofia, Lisboa, v. 56, 2000, p. 515. 
ser representante de alguém. O termo pode adotar esse significado porque o representado está presente por si mesmo na cópia. Representar significa fazer com que algo esteja presente ${ }^{5}$.

Assim, o retorno que Gadamer realiza ao sentido mais básico da representação, entendido como 're-presentar' (Darstellung), pretende indicar uma estrutura básica de sentido que não está circunscrita à relação sujeito e objeto, mas que, ao contrário, possibilita delinear efetivamente o acontecer da experiência da obra de arte, enquanto manifestação na qual tanto o modo de ser do homem quanto o modo de ser da obra se encontram.

Contrapondo-se ao modo como a representação foi vinculada à esfera subjetiva na modernidade (Vorstellung) - estrutura básica da vivência (Erlebnis) e apreensão estéticas, Gadamer entende esse novo modelo (Darstellung) como uma estrutura na qual sujeito e objeto colocam-se numa condição de interdependência e interação. Neste sentido, a subjetividade não é mais considerada como um ponto de partida para pensar nossa relação com a arte, mas antes, é tomada como um dos horizontes de interpretação. Como explica Palmer,

\begin{abstract}
A situação interpretativa não é mais a de uma pessoa que interroga e de um objeto, devendo aquele que interroga construir 'métodos' que lhe tornem acessível o objeto. Pelo contrário, aquele que interroga descobre-se como sendo o ser que é interrogado pelo tema (Sache). Numa situação destas, o 'esquema sujeito-objeto' é enganador, pois o sujeito torna-se agora objeto ${ }^{6}$.
\end{abstract}

Assim, ao apresentar essa nova estrutura representativa como constitutiva da hermenêutica filosófica, Gadamer pressupõe que no evento da compreensão, tal como acontece na experiência da obra de arte, o conteúdo de verdade se manifesta distintamente de qualquer noção de verdade prevista na certeza de um método. Tratase de lidar com a verdade da arte enquanto modo de ser, ou seja, como uma manifestação própria da interação entre intérprete e obra, possibilitando assim novas possibilidades de ser.

${ }^{5}$ GADAMER, Hans-Georg. Verdade e Método I. 5ạ. edição. Petrópolis: Vozes, 2003, p. 202.

${ }^{6}$ PALMER, Richard. Hermenêutica. Lisboa: Ed. 70, 1986, p. 170. 


\section{A experiência hermenêutica da literatura}

A visualização da experiência ontológica da literatura, enquanto experiência hermenêutica, coloca-se para Gadamer em um mesmo horizonte no qual encontramse outras formas de arte, tais como a música, a arquitetura e o teatro, entre outras. De modo específico, sua atenção para com a literatura indica um momento no qual se busca pensar o modo como lidamos, de um ponto vista ontológico, com esta forma de arte fundamentalmente referida à escrita. Nas palavras do próprio Gadamer, "o modo de ser da literatura tem algo de peculiar e incomparável; ela impõe uma tarefa específica para o transformar-se em compreensão. A escrita é estranha para a compreensão"7.

Deste modo a hermenêutica filosófica pretende investigar no fenômeno da literatura uma experiência da verdade na qual o texto não desaparece. Ao contrário, é próprio da literatura a resistência do texto em sua interação com o intérprete como um elemento fundamental à própria experiência hermenêutica da obra literária. Talvez por isso Gadamer nos lembra que "não será por acaso que a palavra literatura não se refere à leitura, mas à escrita" ${ }^{\prime}$. Um dos aspectos próprios da literatura e de sua experiência é o aparecer da escrita enquanto elemento próprio de sua representação (Darstellung). É importante ressaltar que a constituição deste fenômeno se dá no momento de interação entre intérprete e obra, na aparição do texto enquanto obra escrita.

Por um lado, Gadamer trata da literatura de uma forma bastante ampla, isto é, como a pluralidade de escritos relacionados aos mais diversos âmbitos do saber humano, desde a poesia até os textos científicos; por outro lado, Gadamer vê na experiência da literatura a manifestação de uma mesma estrutura representativa reivindicada pela hermenêutica filosófica, que traz nela mesma um modo de ser do texto escrito, enquanto manifestação do compreender e suas mais variadas formas.

Podemos, então, entender a literatura a partir de um elemento próprio a esse fenômeno: seu registro escrito, isto é, sua escritura. Mesmo que a transmissão ou

${ }^{7}$ GADAMER, Hans-Georg. Verdade e Método I. 5a. edição. Petrópolis: Vozes, 2003, p.229.

${ }^{8}$ GADAMER, Hans-Georg. Verdade e Método I. 5a. edição. Petrópolis: Vozes, 2003, p. 225. 
apreciação se dê pelo ato da leitura, há algo que resiste: o texto escrito; este não desaparece no momento da leitura ou recitação. Ao contrário, a escritura se impõe às mais diversas estratégias ou modos de leitura que, ao mesmo tempo, possibilitam uma sempre renovada ressignificação do próprio texto lido. Aqui está em jogo a estrutura representativa na qual a relação entre intérprete e obra permite novas possibilidades de ser.

Deste modo, o modo de ser da literatura, enquanto modo de ser do texto escrito, indica seu caráter único que, segundo o próprio Gadamer, em um texto posterior a Verdade e Método, Texto e Interpretação (1984), vai se referir nos seguintes termos: "Um texto literário exige estar presente em sua manifestação de linguagem e não somente cumprir sua função comunicativa. Não basta lê-lo, é preciso ouvi-lo, mesmo que só com o ouvido interior" 9 .

É necessário, portanto, compreendermos a relação com a literatura de modo diferenciado, principalmente em comparação com as outras artes, pois nesta não há apenas uma mediação compreensiva entre intérprete e texto, mas atua um processo no qual a compreensão da escrita, que passa também pela leitura na qual, enquanto interação com o texto, está em jogo um processo fundamentalmente representativo.

Em outras palavras, a estrutura representativa da literatura, própria do modo como se dá a sua experiência ontológica, requer uma participação do leitor/intérprete que, mesmo diante da resistência do texto enquanto texto, a partir da sua performance, atualiza o modo de ser do texto lido com seus questionamentos e expectativas prévios, encontrando as mais diversas possibilidades de sentido no texto literário escrito, tendo em vista suas demandas.

Em poucas palavras, podemos concluir que é na relação do intérprete com o texto que a literatura se manifesta enquanto obra de arte. Mas de uma forma distinta, por exemplo, do quadro, pois não permanece como referência básica uma imagem original, mas o próprio texto. Como afirma Weinsheimer: “Gadamer insiste que a

${ }^{9}$ GADAMER, Hans-Georg. Verdade e Método II. Petrópolis: Vozes, 2002, p. 407 
literatura pode ser entendida somente como um evento ontológico - isto é, o processo de algo que vem a ser na representação - e não como a experiência de um leitor"10.

Desta forma, podemos afirmar que a condição própria da literatura é a difusão interpretativa do texto escrito pela leitura pois, como diz Gadamer, "de qualquer livro e não só do célebre, pode-se dizer que é para todos e para ninguém"11.

Todavia, o fenômeno da literatura também está relacionado ao leitorintérprete. Isto é, o texto não retém seu sentido em sua condição escrita, mas também depende da interpretação daquele que se dispõe a lê-lo, mesmo que este esteja situado numa época distinta do momento no qual aquele texto foi produzido. Em outras palavras, a literatura, mesmo tendo como prerrogativa o registro escrito, não é uma mera fixação do discurso falado, nem algo remoto e sem sentido. Antes, constituise também a partir do momento de diálogo entre leitor e obra, permitindo assim que o seu sentido se manifeste. Conforme afirma Gadamer,

O conceito de literatura não deixa de estar vinculado a seu receptor. A existência da literatura não é a sobrevivência morta de um ser alienado que se oferece simultaneamente à realidade vivencial de uma época posterior. A literatura é, antes, uma função de preservação e de transmissão espiritual e, por isso, introduz em cada presente sua história oculta ${ }^{12}$.

Sendo assim, na compreensão, enquanto um acontecimento básico, tal como ocorre no caso específico da literatura, há primordialmente a resistência da escrita e não sua dissolução na performance de leitura. Entretanto, este modo de ser do texto, que se manifesta enquanto texto, está fundamentalmente referido ao leitor-intérprete que, ao mesmo tempo, recorre ao texto em diversos momentos da vida comum. Desta forma, se por um lado o texto não desaparece, por outro lado, cada época se relaciona com um mesmo texto de modo distinto, tendo em vista sua condição de resistência.

Neste sentido, o processo compreensivo entre o texto e o intérprete, próprio do evento hermenêutico, acontece de modo sempre renovado, pois o mesmo texto com o qual poderíamos nos relacionar sempre será uma obra sempre atingida por

\footnotetext{
10 WEINSHEIMER, Joel. Gadamer's Hermeneutics: A Reading of Truth and Method. New Haven/ London: Yale University Press, 1985, p. 128.

${ }^{11}$ GADAMER, Hans-Georg. Verdade e Método I. 5ạ. edição. Petrópolis: Vozes, 2003, p. 225.

12 GADAMER, Hans-Georg. Verdade e Método I. 5a. edição. Petrópolis: Vozes, 2003, p. 227.
} 
novos questionamentos, tendo em vista a inteligibilidade de sentido do próprio texto; ao mesmo tempo, a estrutura ontológica do texto, enquanto escritura, coloca-se em uma posição de recepção do leitor, tendo em vista seu modo de ser representativo. Nas palavras de Gadamer: "na leitura do livro permanece uma ocorrência em que o conteúdo lido se torna representação" ${ }^{13}$.

Assim, na relação entre compreensão e literatura, o não desaparecimento do texto - e sua contínua renovação - libera a escrita de qualquer tentativa de domínio metódico. O fenômeno da literatura traz um elemento hermenêutico fundamental: o caráter essencialmente relutante do texto escrito diante do processo hermenêutico no qual a interpretação parece pretender ir além do próprio texto. Cito Gadamer:

\begin{abstract}
É verdade que a literatura e sua recepção na leitura mostram um grau máximo de desvinculação e mobilidade. Sinal disso é que não precisamos ler um livro de uma só vez, de modo que o fato de deixá-lo de lado representa uma tarefa própria da retomada, coisa que não possui correlato no escutar ou no contemplar. Isso permite ver claramente que a "leitura" corresponde à unidade do texto ${ }^{14}$.
\end{abstract}

Para Gadamer, uma obra que faz parte do cânone literário universal encontrase, de algum modo, presente nas consciências de todos, isto é, pertence ao mundo de referências comuns, tanto no momento presente, no qual há novas possibilidades de interpretação, quanto no mundo original do aparecimento deste texto escrito. Diz Gadamer: "É o modo de ser histórico da literatura como tal o que permite que algo pertença à literatura universal" 15 .

Porém, a perspectiva salientada por Gadamer não discute as formas ou critérios de distinção das obras, mas o que a obra efetivamente tem a nos dizer, ou seja, seu modo de ser. Portanto, no pensamento de Gadamer, não é a forma que orienta o pensamento, mas o seu caráter linguístico comum a todos (Sprachlichkeit). Nas palavras do próprio Gadamer: "a capacidade que tem tudo que pertence à linguagem de ascender à escrita circunscreve o sentido mais vasto da literatura"16.

\footnotetext{
${ }^{13}$ GADAMER, Hans-Georg. Verdade e Método I. 5ạ. edição. Petrópolis: Vozes, 2003, p. 226.

${ }^{14}$ GADAMER, Hans-Georg. Verdade e Método I. 5a. edição. Petrópolis: Vozes, 2003, p. 226.

${ }^{15}$ GADAMER, Hans-Georg. Verdade e Método I. 5a. edição. Petrópolis: Vozes, 2003, p.228.

${ }^{16}$ GADAMER, Hans-Georg. Verdade e Método I. 5a. edição. Petrópolis: Vozes, 2003, p. 228.
} 
Deste modo, a literatura poderia ser entendida, na perspectiva do processo compreensivo, como um fenômeno no qual a experiência interpretativa do intérprete revela a condição mais própria da obra, em sua materialidade textual, que, ao mesmo tempo, possibilidade novas possibilidades de ser.

Por fim, na passagem a seguir, Gadamer reivindica a literatura a partir de sua condição peculiar, que não pode ser ignorada pela hermenêutica filosófica mas, ao contrário, deve ser considerada em seu lidar com a questão da compreensão. Cito Gadamer:

\begin{abstract}
O modo de ser da literatura tem algo de peculiar e incomparável; ela impõe uma tarefa específica ao transformar-se em compreensão. Não há nada tão estranho e tão exigente para a compreensão como a escrita. Nem sequer o encontro com pessoas que falam um idioma estrangeiro pode ser comparado com essa estranheza e estranhamento, pois a linguagem dos gestos e o tom de voz comportam um momento de compreensibilidade imediata. A escrita, e a literatura enquanto participa dela, é a compreensibilidade do espírito de tal modo despojada que se situa no que já de mais estranho. Não há nada que possua um caráter espiritual tão puro quanto a escrita, e nada depende tanto do espírito que compreende como ela. ${ }^{17}$
\end{abstract}

\title{
Referências bibliográficas
}

BERNSTEIN, Richard J. Beyond Objectivism and Relativism: Science, hermeneutics and praxis. Oxford: Basil Blackwell, 1983.

BLEICHER, Josef. Hermenêutica Contemporânea. Lisboa: Ed. 70, 1992.

DUQUE-ESTRADA, Paulo Cesar. Is hermeneutics a keyword to characterize Heidegger's thought? Inédito, 2008.

DUQUE-ESTRADA, Paulo Cesar. Limites da Herança Heideggeriana: a Práxis na Hermenêutica de Gadamer. Revista Portuguesa de Filosofia, Lisboa, v. 56, p. 509-520, 2000.

GADAMER, Hans-Georg. Verdade e Método I. 5ạ. edição. Petrópolis: Vozes, 2003.

GADAMER, Hans-Georg. Verdade e Método II. Petrópolis: Vozes, 2002.

PALMER, Richard. Hermenêutica. Lisboa: Ed. 70, 1986.

${ }^{17}$ GADAMER, Hans-Georg. Verdade e Método I. 5a. edição. Petrópolis: Vozes, 2003, p. 228. 
WEINSHEIMER, Joel. Gadamer's Hermeneutics: A Reading of Truth and Method. New Haven/ London: Yale University Press, 1985.

Doutor em Filosofia (PUC-Rio) Professor do PPG de Filosofia (UFPI)

E-mail: silvanobatista@gmail.com 